\title{
Isolation and Properties of an Abnormal Hageman Factor (Factor XII) Molecule in a Cross-reacting Material-positive Hageman Trait Plasma
}

\author{
Hidehiko Saito and Salvatore J. Scialla, Department of Medicine, \\ Case Western Reserve University School of Medicine, University \\ Hospitals of Cleveland, Cleveland, Ohio 44106; \\ Walter Reed Army Medical Center, Washington, D.C. 20012
}

\begin{abstract}
A BSTRACT We have previously described two unrelated individuals with homozygous Hageman trait (Factor XII deficiency) whose plasmas contained nonfunctional material immunologically indistinguishable from normal Hageman factor (HF). Abnormal HF from the plasma of one of these subjects has now been purified to homogeneity, as judged by sodium dodecyl sulfate-polyacrylamide gel electrophoresis, alkaline disc gel electrophoresis, and immunoelectrophoresis. Purified abnormal HF had no clot-promoting activity, but showed the same specific antigenicity as purified normal $\mathrm{HF}$ by an immunoassay. The abnormal HF was of a single chain polypeptide with the same molecular weight $(80,000)$ as normal $\mathrm{HF}$ and was positively stained by periodic acid-Schiff reagent. Both normal and abnormal HF had similar amino acid compositions and isoelectric points (pI $6.5 \sim 7.1$ ). When ${ }^{125}$ I-labeled abnormal HF and ${ }^{131}$ I-labeled normal $\mathrm{HF}$ were mixed with normal plasma and exposed to glass, both $\mathrm{HF}$ underwent an identical pattern of cleavage, yielding 52,000 - and 30,000-mol wt fragments. Similarly, abnormal $\mathrm{HF}$ was fragmented by trypsin in the same way as normal $\mathrm{HF}$, but no prekallikrein-activating activity was generated after cleavage. $\left[{ }^{3} \mathrm{H}\right]$ Diisopropyl phosphorofluoridate was incorporated into a $29,000-\mathrm{mol}$ wt fragment of the trypsin-cleaved normal HF, but not into
\end{abstract}

\footnotetext{
A preliminary report of this study was presented at the Annual Meeting of American Society of Hematology, Phoenix, Ariz., 4 December 1979 (1979. Blood. 54: 280a.).

The opinions or assertions contained herein are the private views of the authors and are not to be construed as official or reflecting the view of the Department of the Army or Department of Defense.

Address reprint requests to Dr. H. Saito, Department of Medicine, University Hospitals of Cleveland.

Received for publication 4 March 1981 and in revised form 8 June 1981.
}

that of the trypsin-cleaved abnormal HF. These data suggest that the molecular defect in this abnormal HF resides at or near the active site serine residue in the $30,000-\mathrm{mol}$ wt part of the molecule.

\section{INTRODUCTION}

Hageman factor (HF, ${ }^{1}$ Factor XII) is a plasma protein that is functionally deficient in plasmas from individuals with Hageman trait. Under certain conditions, HF appears to trigger such surface-mediated plasma reactions as the intrinsic pathway of blood coagulation, contact-activated fibrinolysis, and kinin generations (1).

Although the majority of plasmas of subjects with congenital Hageman factor deficiency also lack immunologically identifiable $\mathrm{HF}$, two unrelated individuals with this disorder have recently been found whose plasmas contained essentially normal amounts of nonfunctional, but immunologically indistinguishable HF (2). Inasmuch as these plasmas contained cross-reacting material (CRM) recognized by the specific antiserum, these cases have been termed $\mathrm{CRM}^{+}$(CRM-positive variant). Elucidation of the nature of the molecular defect in these abnormal HF may provide a unique opportunity to examine the structure-function relationship of this plasma protein.

In the present study, we have isolated an abnormal HF from plasma of an individual with $\mathrm{CRM}^{+} \mathrm{Hage-}$ man trait and have studied some of its properties in

\footnotetext{
${ }^{1}$ Abbreviations used in this paper: BS, barbital-saline buffer, CRM, cross reacting material; DFP, diisopropyl phosphorofluoridate; HF, Hageman factor; LBTI, lima bean trypsin inhibitor; RIA, radioimmunoassay; $R T$, room temperature; SDS-PAGE, sodium dodecyl sulfate-polyacrylamide gel electrophoresis; SP, sulfo-propyl; TLCK, L-choro-tosylamidoamino-heptanone.
} 
comparison with normal HF. This abnormal HF appears to have a defective active site in the light chain of the molecule.

\section{METHODS}

Citrated plasma from normal individuals and subjects with the usual form of Hageman trait were prepared as described earlier (2). Plasmas from an individual with $\mathrm{CRM}^{+}$Hageman trait (subject 2 in ref. 2) were obtained, after informed consent, by plasmaphoresis, using acid-citrate-dextrose (formula A, U. S. Pharmacopeia) anticoagulant. Normal plasma for the isolation of HF was obtained by collecting blood into 1:6 vol of the same anticoagulant.

DEAE-Sephadex A-50, SP-Sephadex C-50, Sephadex G 150, and $\mathrm{CNBr}$-activated Sepharose $4 \mathrm{~B}$ were purchased from Pharmacia Fine Chemicals Inc., Piscataway, N. J. Barbitalsaline buffer (BS) was $0.025 \mathrm{M}$ sodium barbital in $0.125 \mathrm{M}$ sodium chloride at $\mathrm{pH}$ 7.5. Crude immunoglobulin fraction of rabbit anti-HF serum (3) was coupled to $\mathrm{CNBr}$-activated Sepharose 4B according to the manufacturer's instructions.

Hageman factor clot-promoting assays and double-antibody radioimmunoassays (RIA) were performed as described earlier (3). A standard pool of 24 normal male plasmas was prepared by an earlier method (3) and was used as the standard for the measurement of both HF clot-promoting activity and HF antigen (immunoreactive HF). The pooled plasma was arbitrarily said to contain $1.0 \mathrm{U}$ activity/ml and $1.0 \mathrm{U}$ antigen $/ \mathrm{ml}$.

A solid-phase RIA for HF was developed to monitor the $\mathrm{HF}$ antigen of $\mathrm{a} \mathrm{CRM}{ }^{+}$Hageman trait plasma during isolation, since a fluid-phase double-antibody RIA (3) takes a few days to complete and is not suitable for rapid determination during the purification steps. The assay mixture consisted of $0.2 \mathrm{ml} \mathrm{BS}$ containing $0.05 \%$ Tween 20 (Supelco, Inc., Bellefonte, $\mathrm{Pa}$.) and $0.2 \%$ bovine serum albumin (Pentex, Kankakee, Ill.), $0.02 \mathrm{ml}{ }^{125} \mathrm{I}-\mathrm{HF}$ (usually $\sim 12,000 \mathrm{cpm}$ ), 0.05 $\mathrm{ml}$ test material, and $0.1 \mathrm{ml}$ Sepharose-bound anti-HF IgG in a $10 \times 75-\mathrm{mm}$ polystyrene tube. The tube was shaken for $90 \mathrm{~min}$ at room temperature (RT) by a wrist action shaker (Burrell Corp., Pittsburgh, Pa.). Ice-cold BS (1 ml) was then added to the tube and the tube was immediately centrifuged at $1,800 \mathrm{~g}$ for $10 \mathrm{~min}$ at $2^{\circ} \mathrm{C}$. The supernate was discarded, and the precipitated Sepharose was washed and counted for radioactivity in a $\gamma$-counter (model 1085, Nuclear Chicago, Des Plaines, Ill.). The whole procedure took $<3 \mathrm{~h}$. Duplicate determinations were performed for each sample, and serial dilutions of normal pooled plasma were included in each run. A standard curve was prepared by plotting the bound counts per minute against the logarithm of the concentration of $\mathrm{HF}$ and was essentially linear between 1.0 and $0.05 \mathrm{U} \mathrm{HF} / \mathrm{ml}$.

Isolation of the normal and abnormal $\mathrm{HF}$ was carried out essentially by the method of Griffin and Cochrane (4). Purified HF was stored at $4^{\circ} \mathrm{C}$ in $0.05 \mathrm{M}$ sodium acetate buffer ( $\mathrm{pH} 5.2$ ) containing $0.15 \mathrm{M} \mathrm{NaCl}$ and $0.5 \mathrm{mM}$ ethylenediaminetetraacetic acid (EDTA).

Radioiodination of purified normal and abnormal HF with ${ }^{125}$ I and ${ }^{131} \mathrm{I}$ was performed by a chloramine-T method (5). The ${ }^{131}$ I-labeled normal $\mathrm{HF}$ had $1.3 \times 10^{7} \mathrm{cpm} / \mu \mathrm{g} \mathrm{HF}$, and ${ }^{125}$ I-labeled normal HF had $2.5 \times 10^{7} \mathrm{cpm} / \mu \mathrm{g} \mathrm{HF}$. The ${ }^{125} \mathrm{I}-$ labeled abnormal HF had $2.4 \times 10^{7} \mathrm{cpm} / \mu \mathrm{g} \mathrm{HF}$. Protein was estimated by the method of Lowry et al. (6).

Sodium dodecyl sulfate-polyacrylamide gel electrophoresis (SDS-PAGE) was carried out by the method of Weber and Osborn (7), by use of $6 \%$ gels. Gels were stained for protein with Coomassie Blue or for carbohydrate with periodic acidSchiff reagent (8). A low molecular-weight calibration kit
(Pharmacia Fine Chemicals) consisting of six polypeptides of known molecular weight was used to estimate molecular weight.

Analytical disc gel electrophoresis was performed according to a published method (9) using $5 \times 75$-mm gels. Electrophoresis was run at $5 \mathrm{~mA}$ per gel for $45 \mathrm{~min}$, and gels were stained with Coomassie Blue. Replicate gels were frozen and sliced into 2-mm segments, and each segment was incubated with $0.4 \mathrm{ml}$ BS containing $1 \mathrm{mg} / \mathrm{ml}$ bovine serum albumin overnight at $4^{\circ} \mathrm{C}$. The sample was centrifuged and the supernate was assayed for both HF activity and HF antigen.

Isoelectric focusing was carried out by the method of Righetti and Drysdale (10) using $5 \times 120$-mm gels prepared with 6\% acrylamide and 2\% pH 3.5-10 Ampholine (LKB, Stockholm, Sweden). Electrophoresis was performed at $200 \mathrm{~V}$ for $19 \mathrm{~h}$ at RT. The gels were either stained with $0.04 \%$ Coomassie Brilliant Blue G-250 in 3.5\% perchloric acid (11) or sliced into 5-mm segments for $\mathrm{pH}$ determination and for the identification of HF by RIA. Two markers with known isoelectric points (pI), Evans blue (General Diagnostics, Morris Plains, N. J., pI 5.4) and ovalbumin (twice crystallized, Schwarz/Mann, Orangeburg, N. Y., pI 4.7) were run simultaneously for comparison.

Immunodiffusion was performed in a $1 \%$ agarose gel in $0.05 \mathrm{M}$ sodium barbital buffer ( $\mathrm{pH}$ 8.4) for $2 \mathrm{~d}$ at $\mathrm{RT}$. Immunoelectrophoresis was carried out in $1 \%$ agarose gels in $0.05 \mathrm{M}$ sodium barbital buffer (pH 8.4) at a current of $10 \mathrm{~V} / \mathrm{cm}$ for $5 \mathrm{~h}$ at RT. $0.2 \mathrm{ml}$ of the crude immunoglobulin fraction of rabbit anti-HF serum was then placed in the trough, and precipitin lines were allowed to develop over $48 \mathrm{~h}$ at RT.

Amino acid analysis of purified normal and abnormal $\mathrm{HF}$ were carried out with a Durrum D 500 Amino Acid Analyser (Durrum Instrument Corp., Palo Alto, Calif.). Normal or abnormal $\mathrm{HF}(50 \mu \mathrm{g})$ was hydrolyzed at $110^{\circ} \mathrm{C}$ in $6 \mathrm{~N} \mathrm{HCl}$ for $24 \mathrm{~h}$. Half-cystine was determined as cysteic acid (12) after performic acid oxidation. No value for tryptophan was reported, because it is destroyed by acid hydrolysis. The results reported were the average of duplicate determinations.

Cleavage of ${ }^{131} \mathrm{I}$-labeled normal HF, ${ }^{125}$ I-labeled normal HF, and ${ }^{125}$-labeled abnormal $\mathrm{HF}$ in the contact activation of plasma was studied by the method of Revak et al. (13). ${ }^{131}$ Inormal HF (19 ng) and ${ }^{125}$-abnormal HF (14 ng) - $2.5 \mu \mathrm{l} \mathrm{of}$ each-were mixed with $20 \mu \mathrm{l}$ of normal plasma and $175 \mu \mathrm{l}$ of BS in a polystyrene tube. The final plasma dilution was $1: 10$ and the radiolabeled proteins that were added did not increase the plasma content of HF by $>5 \% .20 \mu \mathrm{l}$ of this mixture was added to $10 \times 75-\mathrm{mm}$ glass tubes and shaken at RT for various times. The reactions were terminated by the addition of $50 \mu \mathrm{l}$ of $4 \%$ SDS with or without $4 \% 2$-mercaptoethanol, and the samples were subjected to SDS-PAGE after boiling for $3 \mathrm{~min}$. The zero time sample was obtained by adding the diluted plasma containing radiolabeled HF directly to the SDS solution. Gels were sliced into $2-\mathrm{mm}$ segments, and each slice was counted for ${ }^{131} \mathrm{I}$ and ${ }^{125} \mathrm{I}$ radioactivity with separate windows. ${ }^{125}$ I radioactivity was corrected for the spillover from the ${ }^{131}$ to the ${ }^{125}$ I window. Greater than $90 \%$ of the radioactivity applied to the gel was recovered. Similar experiments were performed by exposing a CRM ${ }^{+}$ Hageman trait plasma containing either ${ }^{125}$ I-abnormal $\mathrm{HF}$ alone, ${ }^{125}$ I-abnormal HF plus nonradioactive normal HF, or 125I-normal HF alone to glass. The results were expresed as the percentage of the radioactivity of each slice relative to the total radioactivity recovered.

Cleavage of ${ }^{131}$ I-labeled normal $\mathrm{HF}$ and ${ }^{125}$ I-labeled abnormal HF by trypsin and generation of the prekallikreinactivating activity was studied by simultaneously following the kinetics of cleavage of $\mathrm{HF}$ by trypsin and the rate of 
generation of prekallikrein-activating activity from HF. A mixture of $1 \mu \mathrm{l}^{131}$ I-normal HF and $60 \mu \mathrm{l}$ normal HF $(2 \mu \mathrm{g})$ was activated with $8 \mu$ l trypsin (80 ng, twice crystallized, salt-free, Worthington Biochemical Corp., Freehold, N. J.) at $37^{\circ} \mathrm{C}$ in a $10 \times 75-\mathrm{mm}$ polystyrene tube. At intervals, the action of trypsin was blocked by $16 \mu \mathrm{l}$ lima bean trypsin inhibitor (LBTI, $160 \mathrm{ng}$, Worthington Biochemicals); the action of activated HF was not inhibited by this concentration of LBTI (14). A 15- $\mu$ l aliquot was then tested for prekallikrein-activating activity by incubating at $0^{\circ} \mathrm{C}$ for 5 min with $300 \mu \mathrm{l}$ of 1:5 diluted HF-deficient plasma. A 50$\mu \mathrm{l}$ portion of this mixture was tested for plasma kallikrein activity by incubating with $2 \mathrm{ml} 0.2 \mathrm{mM} \mathrm{H}$-D-proline phenylalanine-arginine-PNA (S-2302, Kabi Diagnostics, Stockholm, Sweden) at $37^{\circ} \mathrm{C}$ for $10 \mathrm{~min}$. The reaction was terminated by addition of $0.2 \mathrm{ml}$ glacial acetic acid and absorbance at $405 \mathrm{~nm}$ was read. Exactly the same experiment was performed using a mixture of $1 \mu \mathrm{l}{ }^{125} \mathrm{I}$-abnormal $\mathrm{HF}$ and 60 $\mu \mathrm{l}$ abnormal $\mathrm{HF}(2 \mu \mathrm{g})$. To examine the cleavage of $\mathrm{HF}$ by trypsin, 27- $\mu$ l aliquots of the trypsin digests of both normal and abnormal $\mathbf{H F}$ were combined at the indicated time and subjected to SDS-PAGE as described above.

$\left[{ }^{3} \mathrm{H}\right]$ Diisopropyl phosphorofluoridate (DFP) incorporation into trypsin-cleaved normal and abnormal HF was tested by measuring the uptake of $\left[{ }^{3} \mathrm{H}\right] \mathrm{DFP}$ by the normal and abnormal HF after the treatment with trypsin. The conditions for the cleavage of HF by trypsin were identical to those described in the preceding section. $4 \mu \mathrm{g}$ of normal or abnormal $\mathrm{HF}$ was cleaved with $160 \mathrm{ng}$ trypsin in a total volume of $129 \mu \mathrm{l}$ at $\mathrm{pH} 7.5$ at $37^{\circ} \mathrm{C}$ for $10 \mathrm{~min}$. After the action of trypsin had been blocked by addition of $32 \mu$ l LBTI (320 $\mathrm{ng}$ ), the mixture was incubated at $37^{\circ} \mathrm{C}$ for $2 \mathrm{~h}$ with $1 \mathrm{mM}$ DFP containing $100 \mu \mathrm{Ci}$ of $\left[{ }^{3} \mathrm{H}\right] \mathrm{DFP}(6.5 \mathrm{Ci} / \mathrm{mmol}$, Amersham, Arlington Heights, Ill.) in a total volume of $183 \mu$ l. The samples were then extensively dialyzed and subjected to SDS-PAGE after reduction with 2-mercaptoethanol. Control experiments were performed in which HF was first mixed with LBTI and then with trypsin, or HF was replaced by BS. The gels were cut into $2-\mathrm{mm}$ segments and dissolved in $1 \%$ periodic acid (15); after the addition of Aquasol scintillator (New England Nuclear, Boston, Mass.), ${ }^{3} \mathrm{H}$ was measured in a liquid scintillation spectrometer (Nuclear Chicago).

\section{RESULTS}

Isolation of HF from a $\mathrm{CRM}^{+}$Hageman trait plasma. Abnormal HF was isolated from $\sim 300 \mathrm{ml}$ citrated plasma of an individual with $\mathrm{CRM}^{+}$Hageman trait by sequential column chromatography on DEAE-Sephadex A-50, lysine-Sepharose, DEAE-Sephadex A-50, SP-Sephadex C-50, and Sephadex G-150. The last Sephadex G-150 column was used to remove trace amounts of contaminating high molecular-weight proteins from HF. During isolation, localization of immunoreactive HF (HF antigen) was identified by a solid-phase RIA. Approximately $400 \mu \mathrm{g}$ of purified abnormal HF was obtained ( $10 \%$ yield); its specific activity was $23 \mathrm{U}$ immunoreactive $\mathrm{HF}$ per milligram protein by RIA and $0 \mathrm{U} / \mathrm{mg}$ protein in a clot-promoting assay. Normal HF was purified by the same procedure from citrated plasma of a single donor; the purified protein had the specific activity of $22 \mathrm{U}$ immunoreactive $\mathrm{HF}$ per milligram protein and $73 \mathrm{U} / \mathrm{mg}$ protein in the clot-promoting assay. The discrepancy in the specific activities of normal HF between the immunoassay and the clotting assay has been previously noted and is probably due to overestimation of the HF activity of the purified preparation compared to that in whole plasma (3). The elution patterns of abnormal HF from the ion-exchange and gel filtration columns were very similar to those of normal HF. Two separate lots of abnormal HF, isolated on different occasions, were used in the following experiments and gave essentially identical results.

Properties of abnormal HF. A single sharp protein band was observed by SDS-PAGE of both normal and abnormal HF before and after reduction with 2-mercaptoethanol (Fig. 1). These bands were also positively stained with periodic acid-Schiff. The apparent molecular weight estimated by this technique was 80,000 for both normal and abnormal HF. These data indicate that abnormal $\mathrm{HF}$ is a glycoprotein consisting of a single polypeptide chain with the same molecular weight as normal HF.

To show that the band on SDS gels were indeed HF, purified normal and abnormal HF were electrophoresed on nondenatured polyacrylamide gels. The protein band of normal HF appeared at the same place as the HF clot-promoting activity and HF antigen (Fig. 2 A). Similarly, the protein band of abnormal HF was detected at the same place as HF antigen (Fig. 2 B).

Upon immunodiffusion, purified abnormal $\mathrm{HF}$ showed a line of complete identity with purified normal HF against anti-HF serum, and upon immunoelectrophoresis, abnormal HF had the same electrophoretic mobility as its normal counterpart.

The amino acid compositions of abnormal $\mathrm{HF}$ was similar to that of normal HF (Table I). Isoelectric focusing of both normal and abnormal HF demonstrated three distinct protein bands, with pI $6.5 \sim 7.1$ (Fig. 3). Each protein band appeared to be associated with $\mathrm{HF}$ antigen. These amino acid analysis and pI data are essentially similar to those in previous reports (16-18).

Although all these data suggest that abnormal HF is indistinguishable from normal $\mathrm{HF}$ by physicochemical and immunological means, abnormal HF had essentially no clot-promoting function. $12.5 \mathrm{ng}$ of purified normal HF clotted HF-deficient plasma in $76.4 \mathrm{~s}$, and 4,200 ng (336-fold more) abnormal $\mathrm{HF}$, in $250 \mathrm{~s}$ (Table II). The addition of $210 \mathrm{ng}$ abnormal HF to $12.5 \mathrm{ng}$ normal HF did not inhibit the clot-promoting activity of normal HF, which suggests that there was no inhibitor present in abnormal HF.

Cleavage of normal and abnormal HF in the contact activation of plasma. It has been shown that normal human HF, a single chain polypeptide of 80,000 mol wt, undergoes proteolytic cleavage to form 52,000 and 28,000-mol wt fragments upon contact activation in plasma (13). Plasma kallikrein has been assumed 


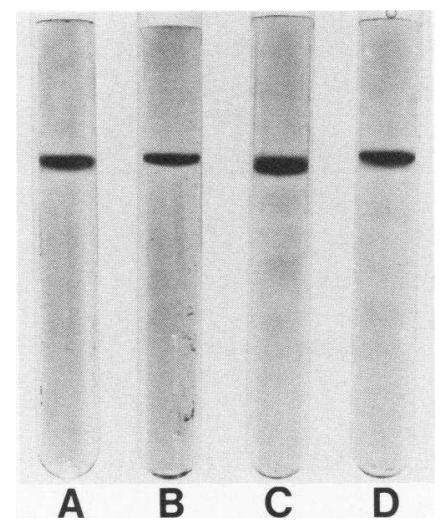

FIGURE 1 SDS-PAGE of purified normal (A and B) and abnormal (C and D) HF. Gels A and B are $5 \mu \mathrm{g}$ of normal HF before and after reduction; gels $C$ and $D$ are $5 \mu \mathrm{g}$ of abnormal $\mathrm{HF}$ before and after reduction, respectively. The anode was at the bottom of the gel.

to be primarily responsible for cleavage of $\mathrm{HF} \mathrm{(13).} \mathrm{We}$ have examined whether abnormal $\mathrm{HF}$ is fragmented in the same way as normal HF. The cleavage of both normal and abnormal HF has been studied in normal plasma and in a $\mathrm{CRM}^{+}$Hageman trait plasma shaken in glass.

Normal plasma containing both ${ }^{131}$ I-labeled normal $\mathrm{HF}$ and ${ }^{125 I}$-labeled abnormal $\mathrm{HF}$ was exposed to glass for varying periods of time and was then subjected to SDS-PAGE before and after reduction with 2mercaptoethanol. The patterns of radioactivity of ${ }^{131} \mathrm{I}$ and ${ }^{125}$ I on gels were then examined (Fig. 4). At zero time, a single large peak representing a native molecule of $80,000 \mathrm{~mol}$ wt was seen in both normal and abnormal HF. After $5 \mathrm{~min}$, the initial peak of both normal and abnormal HF decreased and new peaks appear at 52,000 and $30,000 \mathrm{~mol}$ wt in both reduced and unreduced samples, although more cleavage was found in the presence of the reducing agent (Fig. 4C vis. 4D). These data suggest some scission occurred within
TABLE I

Amino Acid Composition

\begin{tabular}{lcc}
\hline & Normal HF & Abnormal HF \\
\hline & $\%$ & $\%$ \\
Lysine & 3.7 & 3.7 \\
Histidine & 4.7 & 4.8 \\
Arginine & 6.8 & 6.3 \\
Aspartic acid & 6.5 & 6.7 \\
Threonine & 4.9 & 4.5 \\
Serine & 5.9 & 5.3 \\
Glutamic acid & 11.3 & 11.6 \\
Proline & 9.8 & 9.8 \\
Glycine & 8.6 & 8.9 \\
Alanine & 9.1 & 9.5 \\
Half-cystine & 7.4 & 7.1 \\
Valine & 5.3 & 5.0 \\
Methionine & 0.4 & 0.7 \\
Isoleucine & 1.8 & 2.0 \\
Leucine & 8.4 & 8.8 \\
Tyrosine & 2.8 & 2.6 \\
Phenylalanine & 2.6 & 2.6 \\
\hline
\end{tabular}

These values are the average of duplicate determinations.

a disulfide loop yielding fragments connected by disulfide linkages. Under these conditions, the cleavage profile of abnormal HF was identical to that of normal $\mathrm{HF}$ and is in good agreement with those previously reported for normal HF (13).

When a $\mathrm{CRM}^{+}$Hageman trait plasma containing ${ }^{125} \mathrm{I}$-abnormal $\mathrm{HF}$ was exposed to glass, there was no cleavage of abnormal HF detected. However, normal fragmentation of abnormal HF was found when a mixture of ${ }^{125} \mathrm{I}$-abnormal $\mathrm{HF}$ and nonradioactive normal $\mathrm{HF}$ in a $\mathrm{CRM}^{+}$plasma was added to glass. Similarly, normal scission was observed when ${ }^{125}$ I-normal $\mathrm{HF}$ in a $\mathrm{CRM}^{+}$plasma was exposed to glass.

Cleavage of normal and abnormal HF by trypsin and generation of prekallikrein activator activity.

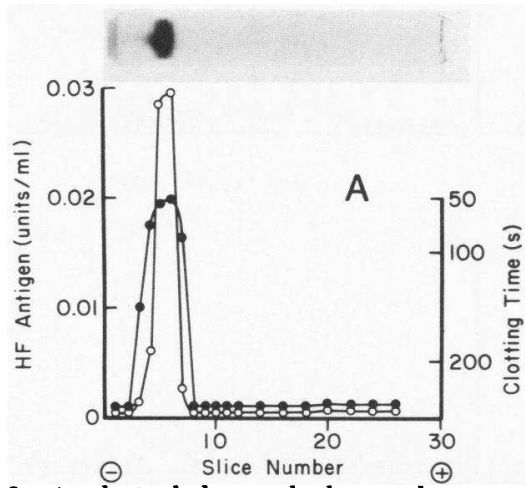

FIGURE 2 Analytical disc gel electrophoresis of purified normal and abnormal HF. $12 \mu \mathrm{g}$ of purified normal HF (A) or $4 \mu \mathrm{g}$ of abnormal HF (B) was electrophoresed in $6 \%$ polyacrylamide as shown on the top panel. Protein was identified by staining with Coomassie Blue. A duplicate gel was sliced into 2-mm segments and assayed for HF clot-promoting activity and antigen as shown in the lower panel. $\mathrm{O}-\mathrm{OHF}$ antigen; $-\mathrm{HF}$ clotting activity. 


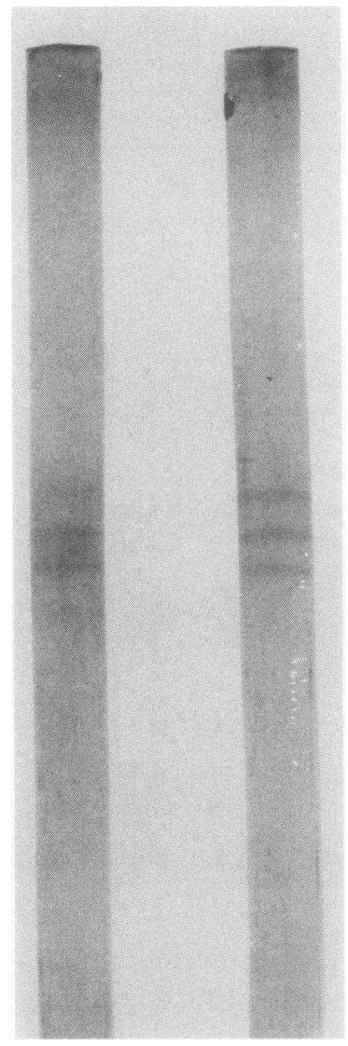

FIGURE 3 Isoelectric focusing of $5 \mu \mathrm{g}$ each of purified normal (right) and abnormal (left) HF. The anode was at the bottom of the gel.

Trypsin is known to cleave normal HF into 52,000-, 40,000 -, and 28,000-mol wt fragments and to generate prekallikrein-activating properties (17). The 28,000 -
TABLE II

Clot-promoting Activity of Purified Normal and Abnormal HF

\begin{tabular}{lr}
\hline \multicolumn{1}{c}{ Test sample } & Clotting time \\
\hline \multicolumn{1}{c}{$n g$} & \multicolumn{1}{c}{$s$} \\
Normal HF, 50 & 55.9 \\
Normal HF, 25 & 65.9 \\
Normal HF, 12.5 & 76.4 \\
Abnormal HF, 4,200 & 250.0 \\
Abnormal HF, 420 & 306.2 \\
Abnormal HF, 42 & $>350.0$ \\
Normal HF, 12.5 + Abnormal HF, 210 & 75.0 \\
Buffer & $>350.0$ \\
\hline
\end{tabular}

$0.1 \mathrm{ml}$ of various concentrations of purified normal or abnormal $\mathrm{HF}$ was assayed for HF clot-promoting activity as described in Methods.

mol wt fragment is a serine protease and carries prekallikrein-activator activity (19-21). When ${ }^{131}$ I-labeled normal HF and ${ }^{125}$ I-labeled abnormal HF were digested with trypsin, both underwent an identical pattern of scission into 52,000-, 40,000-, and 29,000mol wt fragments, as determined by SDS-PAGE (Fig. 5). Potent prekallikein-activator properties were generated when normal HF was digested by trypsin, but were not observed when the abnormal HF was similarly treated; in these experiments, the amidolytic properties of trypsin were blocked by the addition of LBTI before assay. Thus, the failure to generate the enzymatic activity is not due to the lack of the scission.

Incorporation of $\left[{ }^{3} \mathrm{H}\right] D F P$ into trypsin-cleaved normal and abnormal HF. When normal HF was cleaved

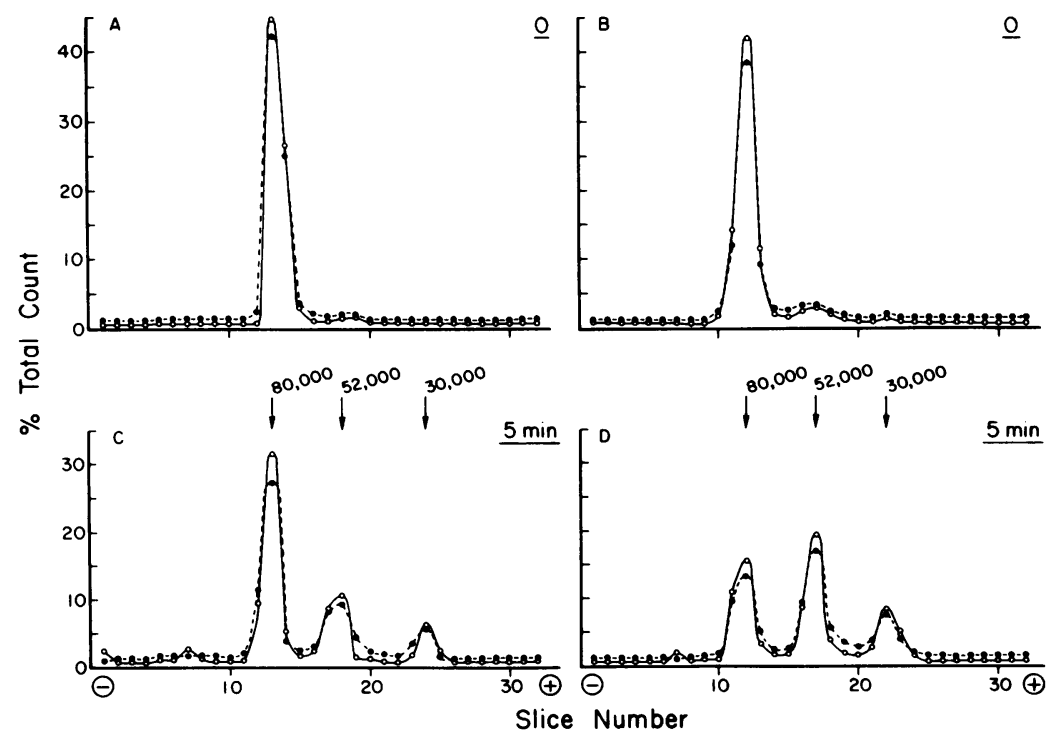

FIGURE 4 SDS-PAGE of ${ }^{131} \mathrm{I}$-normal $\mathrm{HF}$ and ${ }^{125} \mathrm{I}$-abnormal $\mathrm{HF}$ in normal plasma after exposure to glass. (A) 0 time, nonreduced; (B) 0 time, reduced; (C) 5 min, nonreduced; (D) 5 min, reduced. $\mathrm{O} \mathrm{O}^{131} \mathrm{I}$; $0---{ }^{125} \mathrm{I}$. 
and activated by trypsin, a 29,000-mol wt fragment incorporated $\left[{ }^{3} \mathrm{H}\right]$ DFP (Fig. 6). In contrast, a 29,000-mol wt piece from the abnormal $\mathrm{HF}$ failed to take up $\left[{ }^{3} \mathrm{H}\right]$ DFP under the same conditions, although trypsin had cleaved the abnormal HF into 52,000- and 29,000-mol wt fragments, as shown in the preceeding section. In that the 29,000-mol wt part of the molecule has been shown to contain an active site serine in both human and bovine HF (22-24), these data indicate that the molecular defect of the abnormal HF is localized around an active center serine residue in the 29,000-mol wt light chain.

\section{DISCUSSION}

In the present study, an abnormal HF was isolated from plasma of a $\mathrm{CRM}^{+}$Hageman trait subject. The product was homogeneous by several criteria, including SDS-PAGE, alkaline disc gel electrophoresis, and immunoelectrophoresis. The abnormal HF showed complete identity with normal HF upon immunodiffusion against anti-HF serum and had the same specific antigenicity in RIA as normal HF. Thus, the normal and abnormal HF were immunologically indistinguishable. Nonetheless, the abnormal HF was essentially devoid of the clot-promoting activity. We sought to investigate the nature of the defect in this abnormal HF.

Normal HF is a single chain polypeptide of 80,000 mol wt with at least one internal disulfide bridge (17),
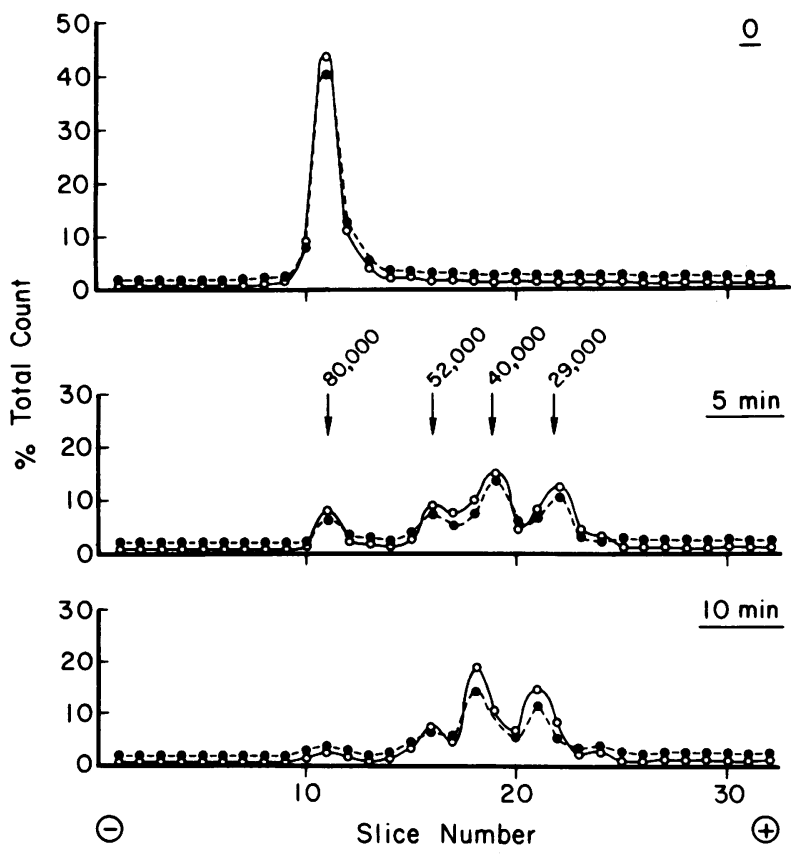

FIGURE 5 SDS-PAGE of ${ }^{131}$ I-normal $\mathrm{HF}$ and ${ }^{125} \mathrm{I}$-abnormal $\mathrm{HF}$ treated with trypsin for varying periods of time. $\mathrm{O}-\mathrm{O}$ ${ }^{131} \mathrm{I} ; 0---{ }^{125} \mathrm{I}$.
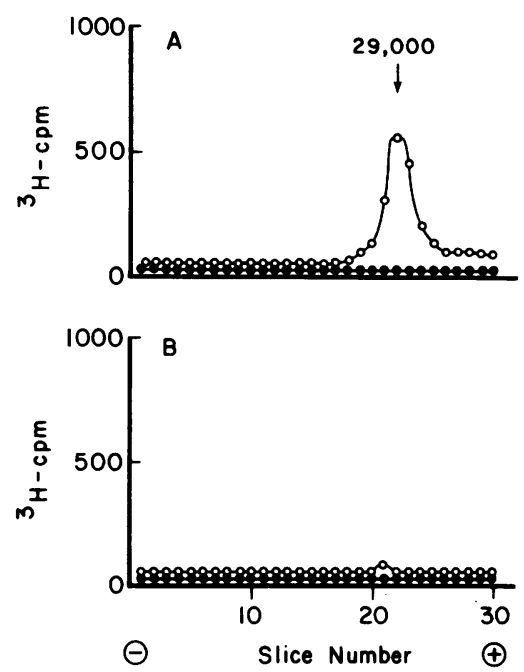

FIGURE 6 Incorporation of $\left[{ }^{3} \mathrm{H}\right] \mathrm{DFP}$ into trypsin-cleaved normal and abnormal HF. $4 \mu \mathrm{g}$ of normal (A) or abnormal (B) $\mathrm{HF}$ was cleaved by $160 \mathrm{ng}$ trypsin and, after trypsin was inhibited by $320 \mathrm{ng} \mathrm{LBTI}$, the mixture was incubated at $37^{\circ} \mathrm{C}$ for $2 \mathrm{~h}$ with $1 \mathrm{~m} \mathrm{M}$ DFP containing $100 \mu \mathrm{Ci}$ of [ ${ }^{3} \mathrm{H}$ ]DFP. After dialysis, the sartiples were analyzed on SDS-PAGE in the presence of 2-mercaptoethanol. $\mathrm{O}-\mathrm{OF}+$ trypsin $\rightarrow$ LBTI; - HF + LBTI $\rightarrow$ trypsin.

and is a zymogen of a serine protease (23-25). When blood comes into contact with such negatively charged surfaces as glass and kaolin, HF, prekallikrein, plasma thromboplastin antecedent (Factor XI), and high molecular-weight kininogen are all adsorbed to the surface and HF becomes enzymatically active. The initial event that triggers the activation of $\mathrm{HF}$ is not yet clear, but it has been postulated that a conformational change in HF molecule upon binding (26), a low degree of inherent enzymatic activity in the HF zymogen (23), or the interaction of $\mathrm{HF}$ with prekallikrein on a surface (a substrate-induced catalysis) (27) may activate a few molecules of HF. Autoactivation of HF. has also been suggested as a trigger $(28,29)$. In any event, once $\mathrm{HF}$ is activated, it in turn activates prekallikrein to kallikrein that further activates HF (reciprocal activation) (30). During these reactions, HF undergoes specific limited proteolytic cleavage, yielding 52,000 mol wt (heavy chain) and 28,000-mol wt fragments (light chain) (13). Cleavage seems to occur at two specific sites in the molecule that are inside and outside of a disulfide bridge. The 28,000-mol wt part of the molecule appears to contain an active serine site, while the 52,000-mol wt part is related to the binding to surfaces (13). Therefore, at least three possibilities may be considered as responsible for the defect in the abnormal nonfunctional HF: $(a)$ an inability to bind to a surface, $(b)$ an inability to be cleaved at specific sites, or $(c)$ a defective active center in the cleaved light chain. 
TABLE III

Summary of Properties of an Abnormal HF

\begin{tabular}{lcc}
\hline & Normal HF & Abnormal HF \\
\hline Molecular weight & 80,000 & 80,000 \\
Periodic acid-Schiff staining & + & + \\
Amino acid composition & \multicolumn{2}{c}{ Similar } \\
pI & $6.5 \sim 7.1$ & $6.5 \sim 7.1$ \\
Immunodiffusion & Complete identity \\
Binding to surfaces & + & + \\
Limited proteolysis in the contact & \multicolumn{2}{c}{} \\
activation of plasma or by trypsin & + & + \\
['H]DFP incorporation & + & - \\
Enzymatic activities* & + & - \\
\hline
\end{tabular}

* Clot-promoting and prekallikrein-activating activities.

Table III summarizes some characteristics of this abnormal HF. Both normal and abnormal HF were glycoproteins consisting of a single polypeptide chain with an apparent molecular weight of 80,000 . The amino acid composition and $\mathrm{pI}$ of abnormal $\mathrm{HF}$ were similar to those of normal HF and are in agreement with those reported previously for the normal molecule (16-18). It should be noted, however, that an amino acid analysis of protein cannot detect a single amino acid substitution. The abnormal $\mathrm{HF}$ was as readily adsorbed to negatively charged surfaces as normal HF (2), and underwent an identical pattern of scission after contact activation in normal plasma or tryptic digestion. Therefore, the functional defect in this abnormal HF did not appear to be due to the failure to adsorb to surfaces or to the absence of the specific cleavages. Very small difference in the size of fragments, however, might not have been detected by the technique used. Furthermore, it should be recognized that the abnormal HF showed no cleavage when exposed to glass in the $\mathrm{CRM}^{+}$Hageman trait plasma from which it had been isolated. This was probably related to the defective reciprocal activation of $\mathrm{HF}$ and prekallikrein (30) in the $\mathrm{CRM}^{+}$Hageman trait plasma in which kallikrein activation was absent. This observation appears to support the hypothesis that $\mathrm{HF}$ is the first molecule to be activated in the interaction of $\mathrm{HF}$, prekallikrein, and surfaces $(1,28,29)$.

We investigated the possibility that the defect in the abnormal HF was at the active site in the light chain by using radioactive DFP, which specifically reacts with an active site serine residue.Upon the scission by trypsin, the abnormal HF did not incorporate $\left[{ }^{3} \mathrm{H}\right]-$ DFP into its 29,000-mol wt fragment, whereas normal HF did. These data indicate that the defect in this abnormal $\mathrm{HF}$ resided at or near an active site serine residue in the light chain of the molecule.

The importance of a histidine as well as a serine residue in the catalytic function has been recognized in some serine proteases such as trypsin and plasmin
$(31,32)$. Both trypsin and plasmin contain a single DFPsensitive serine and a single L-1-chloro-3-tosylamido7-amino-2-heptanone (TLCK)-sensitive histidine at their active center. The modification of a histidine residue in the active center of trypsin abolished the incorporation of DFP into an active site serine (31). Thus, the failure of abnormal $\mathrm{HF}$ to take up $\left[{ }^{3} \mathrm{H}\right]-$ DFP may have been due to a substitution at either a serine or histidine residue assuming that activated HF is a trypsinlike enzyme. Although it would be interesting to study the incorporation of radioactive TLCK into normal and abnormal HF, radioactive TLCK is not available at the present time.

\section{ACKNOWLEDGMENTS}

We thank Dr. O. D. Ratnoff for his encouragement and support, Dr. R. W. Hogg, Department of Microbiology, Case Western Reserve University School of Medicine, for amino acid analysis, and Ms. Susan Gifford and Miss Thea Palmer for their invaluable technical assistance.

This work was supported in part by research grant HL01661 from the National Heart, Lung, Blood Institute, The National Institutes of Health, U. S. Public Health Service, and in part by grants from the American Heart Association, and its Northeast Ohio Affiliate.

\section{REFERENCES}

1. Ratnoff, O. D., and H. Saito. 1979. Surface-mediated reactions. Curr. Top. Hematol. 2: 1-57.

2. Saito, H., J. G. Scott, H. Z. Movat, and S. J. Scialla. 1979. Molecular heterogeneity of Hageman trait (factor XII deficiency). Evidence that two of 49 subjects are crossreacting material positive $\left(\mathrm{CRM}^{+}\right)$. J. Lab. Clin. Med. 94: $256-265$.

3. Saito, H., O. D. Ratnoff, and J. Pensky. 1976. Radioimmunoassay of human Hageman factor (factor XII). J. Lab. Clin. Med. 88: 506-514.

4. Griffin, J. H., and C. G. Cochrane. 1976. Human factor XII (Hageman factor). Methods Enzymol. 45: 56-65.

5. McConahey, P. J., and F. J. Dixon. 1966. A method of trace iodination of proteins for immunologic studies. Int. Arch. Allergy Appl. Immunol. 29: 185-189.

6. Lowry, O. H., N. J. Rosebrough, A. L. Farr, and R. J. Randall. 1951. Protein measurement with the Folin phenol reagent. J. Biol. Chem. 193: 265-275.

7. Weber, K., and M. Osborn. 1969. The reliability of molecular weight determination by dodecyl sulfatepolyacrylamide gel electrophoresis. J. Biol. Chem. 244: 4406-4412.

8. Fairbanks, G., T. L. Steck, and D. F. H. Wallach. 1971. Electrophoretic analysis of the major polypeptides of the human erythrocyte membrane. Biochemistry. 10: 26062617.

9. Davies, B. J. 1964. Disc electrophoresis II. Method and application to human serum protein. Ann. N. Y. Acad. Sci. 121: 404-427.

10. Righetti, P. G., and J. W. Drysdale. 1971. Isoelectric focusing in polyacrylamide gels. Biophys. Biochim. Acta. 236: $17-25$.

11. Reisner, A. H., P. Nemes, and C. Bucholtz. 1974. The use of Coomassie brilliant blue G 250 perchloric acid solution for staining in electrophoresis and isoelectric 
focusing on polyacrylamide gels. Anal. Biochem. 64: $509-516$.

12. Hirs, C. H. W. 1967. Determination of cystine as cysteic acid. Methods Enzymol. 11: $197-199$.

13. Revak, S. D., C. G. Cochrane, and J. H. Griffin. 1977. The binding and cleavage characteristics of human Hageman factor during contact activation. J. Clin. Invest. 59: 1167-1175.

14. Ratnoff, O. D. 1981. Studies on the inhibition of ellagic acid-activated Hageman factor (factor XII) and Hageman factor fragments. Blood. 57: 55-58.

15. Anker, H. S. 1970. A solubilizable acrylamide gel for electrophoresis. FEBS (Fed. Eur. Biochem. Soc.) Lett. 7: 293.

16. McMillin, C. R., H. Saito, O. D. Ratnoff, and A. G. Walton. 1974. The secondary structure of human Hageman factor (Factor XII) and its alteration by activating agents. J. Clin. Invest. 54: 1312-1322.

17. Revak, S. D., C. G. Cochrane, A. R. Johnston, and T. E. Hugli. 1974. Structural changes accompanying enzymatic activation of human Hageman factor. J. Clin. Invest. 54: 619-627.

18. Spragg, J., A. P. Kaplan, and K. F. Austin. 1973. The use of isoelectric focusing to study components of the human plasma kinin-forming system. Ann. N. Y. Acad. Sci. 209: 372-386.

19. Kaplan, A. P., and K. F. Austen. 1970. A pre-albumin activator of prekallikrein. J. Immunol. 105: 802-811.

20. Wuepper, K. D., E. S. Tucker, and C. G. Cochrane. 1970. Plasma kinin system: proenzyme components. J. Immunol. 105: 1307-1311.

21. Soltay, M. I., H. Z. Movat, and A. H. Ozge-Anwar. 1971. The kinin system of human plasma $\mathrm{V}$. The probable derivation of prekallikrein activator from activated Hageman factor (XIIa). Proc. Soc. Exp. Biol. Med. 138: 952-958.
22. Wuepper, K. D. 1972. Biochemistry and biology of components of the plasma kinin-forming system. In Inflammation. I. H. Lepow and P. A. Ward, editors. Academic Press, Inc., New York. 93-117.

23. Griffin, J. H., and G. Beretta. 1979. Molecular mechanisms of surface-dependent activation of Hageman factor (factor XII). In Kinins II. S. Fujii, H. Moriya, and T. Suzuki, editors. Plenum Publishing Corp., New York. 39-51.

24. Fujikawa, J., K. Kurachi, and E. W. Davie. 1977. Characterization of bovine Factor XIIa (activated Hageman factor). Biochemistry. 16: 4182-4188.

25. Meier, H. L., J. V. Pierce, R. W. Colman, and A. P. Kaplan. 1977. Activation and function of human Hageman factor. The role of high molecular weight kininogen and prekallikrein. J. Clin. Invest. 60: 18-31.

26. Ratnoff, O. D., and H. Saito. 1979. Amidolytic properties of single-chain activated Hageman factor. Proc. Natl. Acad. Sci. U. S. A. 76: 1461-1463.

27. Heimark, R. L., K. Kurachi, K. Fujikawa, and E. W. Davie. 1980. Surface activation of blood coagulation, fibrinolysis and kinin formation. Nature (Lond.). 286: 456-460.

28. Wiggins, R. C., and C. C. Cochrane. 1979. The autoactivation of rabbit Hageman factor. J. Exp. Med. 150: $1122-1133$.

29. Silverberg, M., J. T. Dunn, L. Garen, and A. P. Kaplan. 1980. Autoactivation of human Hageman factor. J. Biol. Chem. 255: 7281-7286.

30. Cochrane, C. G., S. D. Revak, and K. D. Wuepper. 1973. Activation of Hageman factor in solid and fluid phases. A critical role of kallikrein. J. Exp. Med. 138: 1564-1583.

31. Beeley, J. G., and H. Neurath. 1968. The reaction of trypsin with bromoacetone. Biochemistry. 7: 1239-1249.

32. Groskopf, W. R., B. Hsieh, L. Summaria, and K. C. Robbins. 1969. Studies on the active center of human plasmin. The serine and histidine residues. J. Biol. Chem. 244: 359-365. 